\title{
Author Correction: Growing a social brain
}

Shir Atzil $\mathbb{D}$, Wei Gao, Isaac Fradkin and Lisa Feldman Barrett

Correction to: Nature Human Behaviour https://doi.org/10.1038/s41562-018-0384-6, published online 6 August 2018.

In the version of this Perspective originally published, at the end of the first paragraph of the section 'Neural prediction as a potential mechanism for how experience sculpts the developing brain' the citation to ref. 76 should have been to ref. 74, and at the end of the first sentence of the next paragraph ref. 76 should have been cited alongside ref. 74 . These have now been corrected.

Published online: 22 August 2018

https://doi.org/10.1038/s41562-018-0431-3 